\title{
Event-related synchronization/desynchronization in terms of manual motor program switching in men
}

Olha Korzhyk*,

Olha Pavlovych,

Lyudmyla Shvarts,

Tetyana Shevchuk,

Olena Dmytrotsa,

Andriy Poruchynskiy,

Alevtyna Morenko

Department of Human and Animal Physiology,

Lesya Ukrainka Eastern

European National University,

13 Volya Avenue,

Lutsk 43025, Ukraine
The scientific community is paying increasing attention to the characteristics of brain processes providing switch of manual motor programs. Thirty-two right-handed men aged $18-23$ years participated in the experiment. The EEG registration was performed according to the international system 10/20, with closed eyes during manual reactions in the Go-Stop-Change paradigm. In the case of a low tone $(70 \%)$, men had to press the left button of the console (go-response) with the right index finger. A high tone (30\%) required rapid pressing of the right button (stop-change-response) with the middle finger. Event-related desynchronization and synchronization of the spectral power of the EEG frequency ( $6 \mathrm{~Hz}$ to $23 \mathrm{~Hz}$ ) were estimated in the Matlab environment. Significant ERS response is established at the frequency of $6 \mathrm{~Hz}$ in symmetrical frontal, central and parietal parts, at $9 \mathrm{~Hz}$ - in the left parietal area, at $14-15 \mathrm{~Hz}$ - in frontal, central, and parietal areas of the right cortex, and at the frequency of $22 \mathrm{~Hz}$ - in the right frontal lobe. However, EEG desynchronization is recorded at the frequency of $7-8 \mathrm{~Hz}$ in the frontal and central areas of both hemispheres. The most sensitive to the manual movement stop followed by switching to an alternative event is associated with synchronization of electrical cortical activity, which showed higher values of the spectral power at the frequency of $6 \mathrm{~Hz}$ and 14-15 Hz in frontal and central allocations, and was lower at the frequency of $16-17 \mathrm{~Hz}$ in both parietal lobes than that during the Go-response.

Keywords: Go/Stop-Change paradigm, finger movements, spectral power, electroencephalogram, frequency spectrum

\section{INTRODUCTION}

In everyday life of each human, the stops in movements, which are not accompanied by the subsequent switching to an alternative answer, are rare. To study the above-mentioned processes,

\footnotetext{
*Corresponding author. Email: olga.korgik@gmail.com
}

an extended version of the go-no go paradigm the so-called Go-Stop-Change paradigm (Logan, 1994) - is proposed. According to Logan (1994), the Go-Stop-Change paradigm can explain the physiological mechanisms of process inhibition in the context of its future changes. Based on this paradigm, research of Band and van Boxtel (1999), Boecker et al. (2011), Rangel-Gomez et al. 
(2015) implies that the overall breaking distance is at the basis of stop and change of the motor response. Response time to stop and change answers was practically the same; however, they were considerably faster than the response to the go stimulus. Analyzing visualization data, Boecker and his colleagues (2011) found out that the processes of stopping and switching movement launched similar activation models.

Contrary to those results, other authors (De Jong et al., 1995; Krämer et al., 2011) insist, on the basis of behavioural and electrophysiological results, on the existence of various mechanisms of response standstill and its stopping with the following alternative answer. The researchers found out that the response time to the changestimuli was significantly higher than to the stopstimuli. However, typical negativity, associated with inhibition (N2), was only during stop-tasks.

Controversial data are shown in recent studies of Rangel-Gomez et al. (2015). Their results indicate that the inhibitory process in the changecondition is significantly faster than in the stopcondition. However, they found no differences between stop and change objectives for frontal and central N2. The study confirmed the importance of the back mid-rear frontal areas in response inhibition and generally indicates a single mechanism of motor response stop/change.

Several authors - Camalier et al. (2007), Verbruggen et al. (2008), M. Boecker et al. (2013) - made a conclusion that the obtained experimental results could be better explained by assuming that the go-response is inhibited by the stop process activation. In addition, the authors assumed that the alternative goresponse is activated only after the stop process.

Thus, current literature data indicate that there is still a real shortage of research and a considerable controversy regarding questions about the same or different brain mechanisms, which are associated with the inhibition of previous goresponse and alternative motor objective which are involved in the situation of stop-processes in a pure form and in the situation stop-changeresponse. Taking into consideration the results of current literature (Camalier et al., 2007; Verbruggen et al., 2008; Boecker et al., 2013), in our study we proceeded from the fact that all three processes (go-response, stop-process, and the second go-response) could actually be considered as independent. In this context, comparisons of cortical activity during the go-response in terms of stops followed by switching to alternative motor objective can show specific EEG markers of that process.

The purpose of the study was to evaluate the event-related synchronization/desynchronization of EEG spectral power in terms of inhibition of running motor program of manual movement, followed by switching to alternative motor objective.

\section{MATERIALS AND METHODS}

\section{Participants}

Thirty-two men, aged 18-23 years, participated in the experiment. They did not have any neuropsychiatric disorders or traumatic brain injuries in their anamnesis. Participation in the experiment was carried out on a voluntary basis and corresponded to all common bioethical standards.

\section{Psychophysiological testing}

The experiment was carried out in two stages psycho-physiological and electroencephalographic.

During the first, phycho-physiological, phase, the health status, the profile of manual and auditory symmetries, and the time of sensorimotor reactions were observed. The health state of men was determined with the help of a questionnaire on wellbeing, activity, and mood (WAM). Taking into account the nature of the responses in the survey, motor performance, and acoustic tests, the index of manual and auditory asymmetry was calculated for each participant $\left(\mathrm{K}_{\text {sk. }}\right)$ (Zhavoronkova, 2009):

$$
\mathrm{K}_{\text {skew }}=\frac{\Sigma_{\text {right }}-\Sigma_{\text {left }}}{\Sigma_{\text {right }}+\Sigma_{\text {left }}} \times 100 \%,
$$

where $\Sigma_{\text {right }}$ - the amount of tasks where the right hand (right ear) is dominating during their execution, $\Sigma_{\text {left }}$ - the amount of tasks where the left hand (left ear) is dominant. 
Further studies involved dextral testees whose coefficients of manual and auditory asymmetries were positive and were above $50 \%$. There were 25 men in all.

The time of sensorimotor response was determined by the computer diagnostic complex "Diagnost-1" (Certificate of measuring equipment type No. UA-MI/2p-2613-2008, of 5 August 2008). According to the instructions, an examinee is expected to press and release, as fast as possible, the button panel when a signal - a geometric shape - appears on the screen.

\section{EEG experiment procedure}

During the second, electroencephalographic, stage, participants were in a specially-equipped sound- and lightproof room, in a reclining position with closed eyes. Prior to that, each examinee received an instruction according to which he had to press and release the left button of the console (go-response) quickly with the right index finger upon hearing a low tone (a sound of $600 \mathrm{~Hz}$ ). In the case of a high tone (1600 Hz sound), an examinee was required to rapidly press and release the right button of the console (stop-change-response) with his middle finger. Under experimental conditions, all stimuli sounds were served in pairs. In some stimuli pairs both sounds were low-pitched, in others the first sound was a low tone, and the second a high tone. In each case, the exami- nees started moving their right index fingers at the first sound. The second sound in the stimuli pair had the value or confirmation movement (Go) or its stop and switching to the alternative motor task (Stop-Change) with the middle finger of the right hand (Fig. 1).

The duration of each sound was $50 \mathrm{~ms}$, each interval between stimuli pairs was $5000 \mathrm{~ms}$. The correlation of the stimuli pairs with both low sounds $(600 \mathrm{~Hz})$ and the stimuli pairs with both low and high sounds $(600 \mathrm{~Hz}$ and $1600 \mathrm{~Hz}$ ) in the sample was 70/30. In each stimuli pair time, the delay before the second sound after the first sound was $140 \mathrm{~ms}$. This period included the hidden time of sensorimotor responses, which are related to the signal perception, the analysis, the decision-making on the motion, and formation of motor programs (Lizogub et al., 2015; Rangel-Gomez et al., 2015).

\section{Registration and processing of EEG data}

EEG recording was performed using electroencephalographic hardware and software complex "Neurokom" (Certificate of compliance with technical regulations on medical devices No. 753, of 25 January 2017). EEG registration was performed monopolar. Nineteen active electrodes were placed on the surface of the scalp, according to the international system 10/20. Combined ear electrodes A1 and

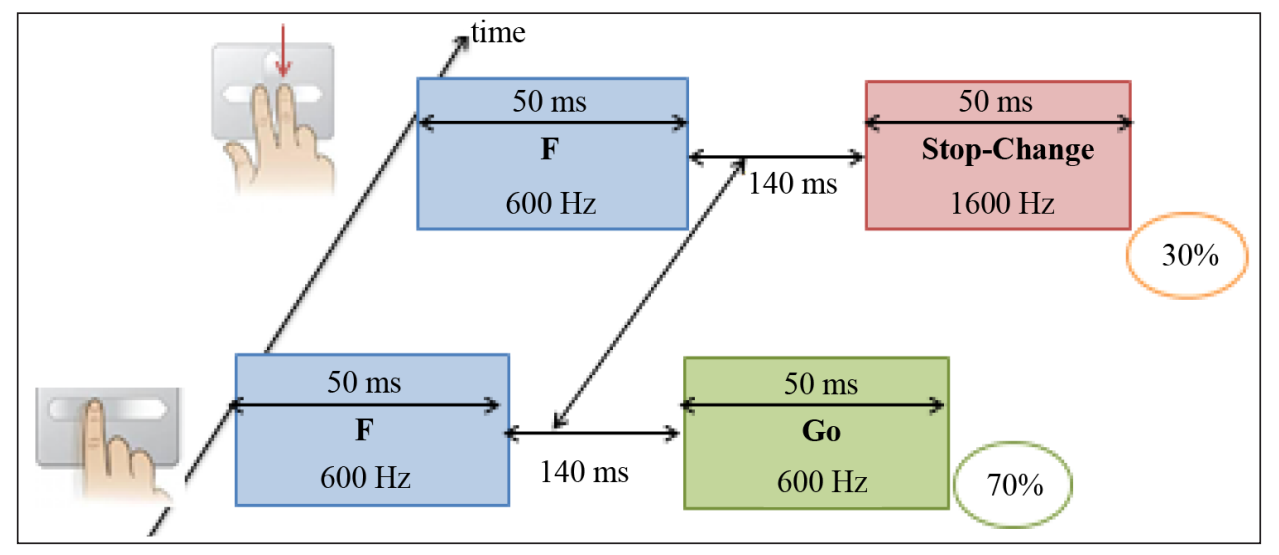

Fig. 1. Scheme of the paradigm Go-Stop/Change of the conducted experiment

F - the first sound in the stimuli pair, in response to which the examinee had to start moving, Go or Stop-Change - the second sound in the stimuli pair, which has value and confirms the initiated movement (Go) or stop initiated movement and switch to an alternative one (Stop-Change), $70 \%$ and 30\% - correlation between the stimuli pairs in the sample. 
A2 were attached to the left and right ear lobes, respectively. They were used as reference electrodes. Additionally, referential electrodes Ref were used (placed between frontal and lateral parts and N (Nasion)). Artefact activity rejection of native EEG was carried out by applying ICA (Independent Component Analysis).

Changes in brain activity were measured in the frontal (F3, F4), central (C3, C4), and parietal (P3, P4) leads. The choice of such assignments is associated with the existing published data that demonstrate the outstanding part of these cortical areas in the processing of motor data and motor programming (Haaland et al., 2000; Ioffe, 2003; Ou Bai, 2005; Neubauer et al., 2006; Morenko et al., 2013).

Desynchronization (event-related desynchronization, ERD) and synchronization (event-related synchronization, ERS) of spectral power (SP) of EEG frequency $(6 \mathrm{~Hz}$ to $23 \mathrm{~Hz}$ ) were estimated. Calculation of ERD/ ERS maps was conducted in the Matlab environment (MathWorks, 2015) in accordance with the procedure described by Pfurtscheller \& Lopes da Silva (1999). The content of the technique ERD/ERS was as follows: (1) collection of EEG data for $\mathrm{N}$ stimulus presentation was conducted; (2) the signals were sequentially filtered for the analysis of all $\mathrm{N}$ stages; (3) the filtered signals were squared for calculation of the signal strength for each reference of each stage; (4) the received power levels for each period of time in the analysis were summarized for all stages (point-to-point); (5) the calculation of ERD/ERS was repeated for several consecutive frequency ranges in increments of $1 \mathrm{~Hz}$. The received values of changes in the spectral power EEG were represented in a variety of colours of the spectrum, which resulted in ERD/ERS maps. The stage of analysis was $5 \mathrm{~s}$, which included $2 \mathrm{~s}$ before the submission of the second sound in the stimuli pair (reference interval) and $3 \mathrm{~s}$ after the filing (post stimuli interval). The change in the spectral power (SP) EEG was evaluated in regard to a referential time interval. Within the period of post-stimuli interval, the period of sensorimotor response of the examinees was analyzed.
In terms of Stop-Change-response and its differences, ERD/ERS analysis was conducted for each participant if compared with those in the Go-response.

\section{Statistical processing of the results}

Selection criteria for statistical analysis were based on the purpose of research and were determined by the distribution of the obtained numerical data. Test samples for normality of the distribution were carried out using criteria of Shapiro Wilka (W, at $p>0.05$ ). Since not all samples had normal distribution, the differences were evaluated by Wilcoxon criteria. Differences at $p \leq 0.05$ are considered reliable. Changes in SP EEG frequency components in each lead in terms of motor response and its stop with the following switching to an alternative answer were analyzed. Statistical analysis was conducted in Statistica 8.0 software (StatSoft. Inc).

\section{RESULTS}

\section{Results of psycho-physiological testing}

The obtained average assessments of the overall functional status of the participants at the time of the experiment conducted according to the WAM test were the following: wellbeing $-5.82 \pm 0.16$, activity $-5.18 \pm 0.16$, mood $-5.68 \pm 0.16$. It allows confirming the vigorous state of the participants and the possibility of their participation in electroencephalographic study. The time of the mere sensorimotor response in the group of participants was $258.8 \mathrm{~ms} \pm 10.22 \mathrm{~ms}$.

\section{Analysis of changes in the EEG spectral power in terms of the Stop-Change response} According to the obtained results, a significant ERS reaction was established in symmetric frontal, central and parietal parts at the frequency of $6 \mathrm{~Hz}(p \leq 0.05)$, which corresponds to the upper $\theta$-subrange of EEG (Table, Fig. 2-4).

According to the obtained results, the generalized reaction ERS in the upper $\theta$-range $(6 \mathrm{~Hz})$ EEG in frontal, central and parietal cortical lobes of both hemispheres was 
Table. Significant changes in EEG spectral power in men in terms of the Stop/Change response

\begin{tabular}{|c|c|c|c|c|c|}
\hline \multirow{7}{*}{ F3 } & Frequency & $p$-value & \multirow{7}{*}{$\mathrm{F} 4$} & Frequency & $p$-value \\
\hline & $6 \mathrm{~Hz}$ & 0.00002 & & $6 \mathrm{~Hz}$ & 0.00002 \\
\hline & $7 \mathrm{~Hz}$ & 0.004 & & $7 \mathrm{~Hz}$ & 0.007 \\
\hline & $8 \mathrm{~Hz}$ & 0.0001 & & $8 \mathrm{~Hz}$ & 0.0001 \\
\hline & $14 \mathrm{~Hz}$ & 0.02 & & $14 \mathrm{~Hz}$ & 0.03 \\
\hline & \multirow{2}{*}{$15 \mathrm{~Hz}$} & 0.01 & & $15 \mathrm{~Hz}$ & 0.02 \\
\hline & & & & $22 \mathrm{~Hz}$ & 0.02 \\
\hline \multirow{6}{*}{$\mathrm{C} 3$} & Frequency & $p$-value & \multirow{6}{*}{$\mathrm{C} 4$} & Frequency & $p$-value \\
\hline & $6 \mathrm{~Hz}$ & 0.00002 & & $6 \mathrm{~Hz}$ & 0.00002 \\
\hline & $7 \mathrm{~Hz}$ & 0.008 & & $7 \mathrm{~Hz}$ & 0.01 \\
\hline & $8 \mathrm{~Hz}$ & 0.002 & & $8 \mathrm{~Hz}$ & 0.004 \\
\hline & $14 \mathrm{~Hz}$ & 0.03 & & $14 \mathrm{~Hz}$ & 0.04 \\
\hline & $15 \mathrm{~Hz}$ & 0.03 & & & \\
\hline \multirow{3}{*}{ P3 } & Frequency & $p$-value & \multirow{3}{*}{$\mathrm{P} 4$} & Frequency & $p$-value \\
\hline & $6 \mathrm{~Hz}$ & 0.0001 & & $6 \mathrm{~Hz}$ & 0.0002 \\
\hline & $9 \mathrm{~Hz}$ & 0.04 & & $14 \mathrm{~Hz}$ & 0.05 \\
\hline
\end{tabular}

revealed, which was significantly higher when compared with the Go-response. This pattern may indicate memory improvement, it allows keeping the information about sensory stimuli in focus, and provides movements in terms of the stop-change-response (Klimesch et al., 2007). In addition, the increase in the oscillatory activity in $\theta 2$-subrange of the EEG may reflect a generally difficult course of the sen- sorimotor response in conditions which included a strengthening of downward control associated with the processes of (re)programming in the prefrontal and the primary motor cortex.

Instead, the frequency of $7-8 \mathrm{~Hz}$ (low range of $\alpha$-activity) in the frontal ( $p \leq 0.05)$ and central $(p \leq 0.05)$ areas of both hemispheres recorded event-related EEG desynchronization.

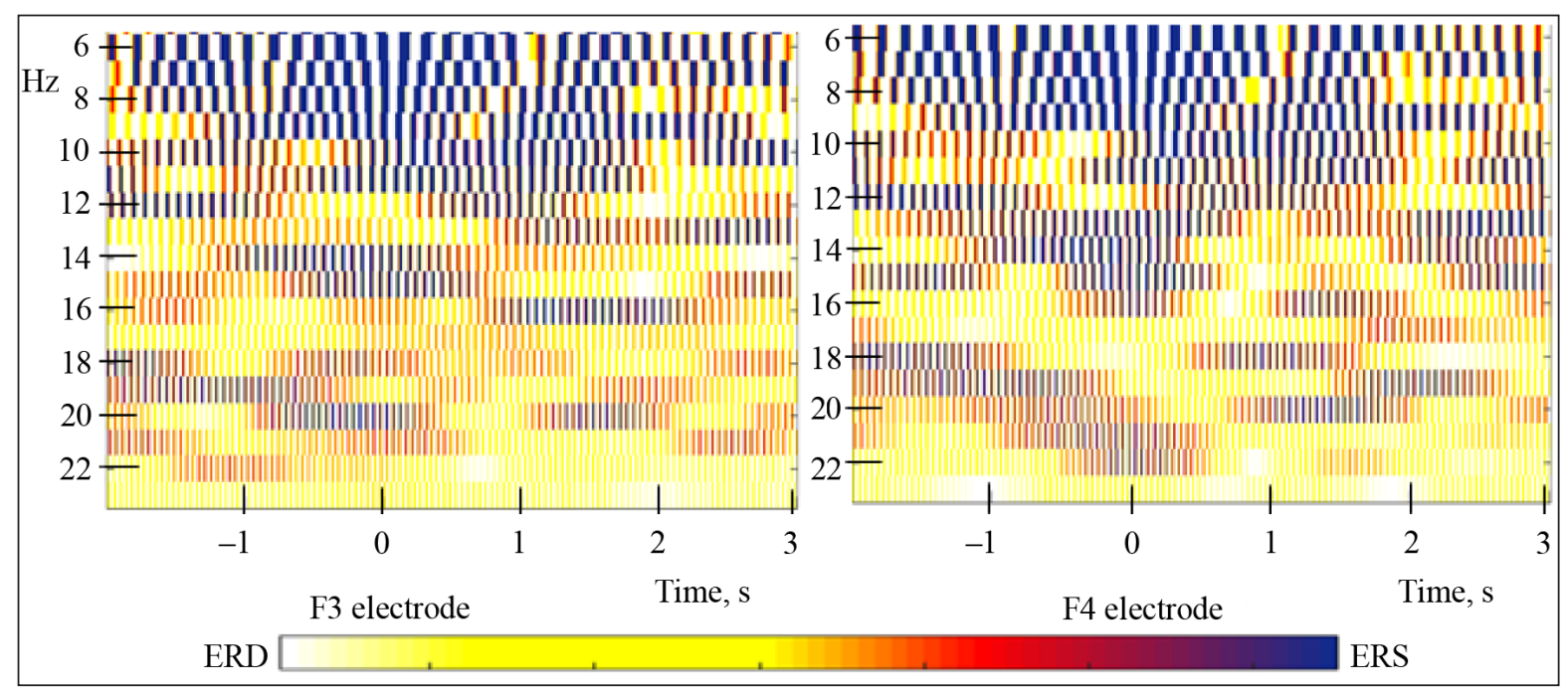

Fig. 2. ERD/ERS maps of frequency spectrum EEG in frontal leads in terms of the Stop-Change-response in men 


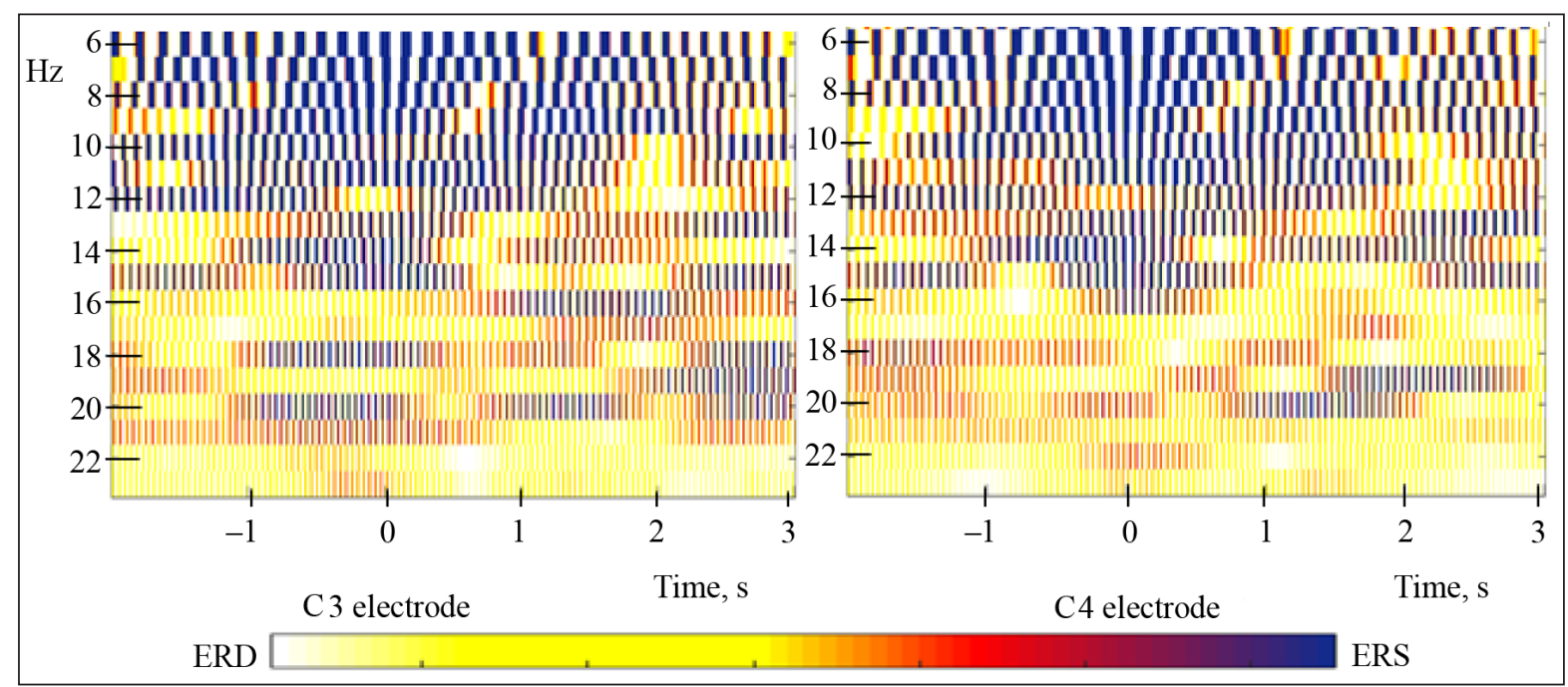

Fig. 3. ERD/ERS maps of frequency spectrum EEG in central leads in terms of the Stop-Change-response in men

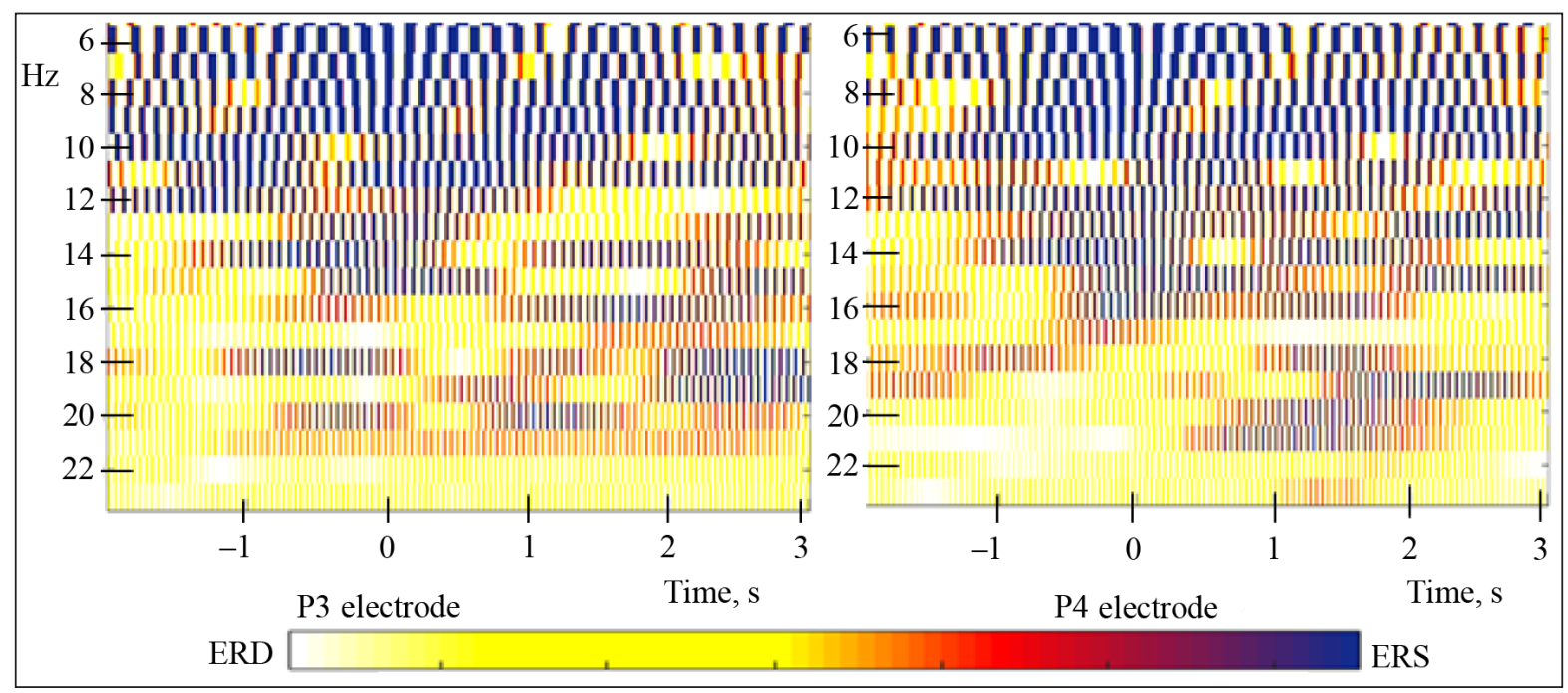

Fig. 4. ERD/ERS maps of frequency spectrum EEG in parietal leads in terms of Stop-Change-response in men

Noteworthy is the registered ERS response at the frequency of $9 \mathrm{~Hz}$ in the left, contralateral to the movement, parietal area $(p \leq 0.05)$. The processes of a related synchronization event of electrical activity at frequencies of 14$15 \mathrm{~Hz}$ ( $\beta 1$-subrange) were found in the frontal, central, and parietal areas of the right cortex $(p \leq 0.05)$, at the frequency of $22 \mathrm{~Hz}(\beta 2$ subrange) - in the right frontal leads $(p \leq 0.05)$ (Table, Figs. 2-4).
In terms of the stop-change response, it was found that the processes related to the event of synchronization in the right frontal and central areas at frequency $6 \mathrm{~Hz}$, and both left frontal and central areas at the frequency of $14 \mathrm{~Hz}$ were significantly higher than those provided by the go-response $(p \leq 0.05)$. Instead, in symmetrical parietal leads at the frequency of 16$17 \mathrm{~Hz}$ of EEG ERS response was relatively lower $(p \leq 0.05)$ (Fig. 5). 


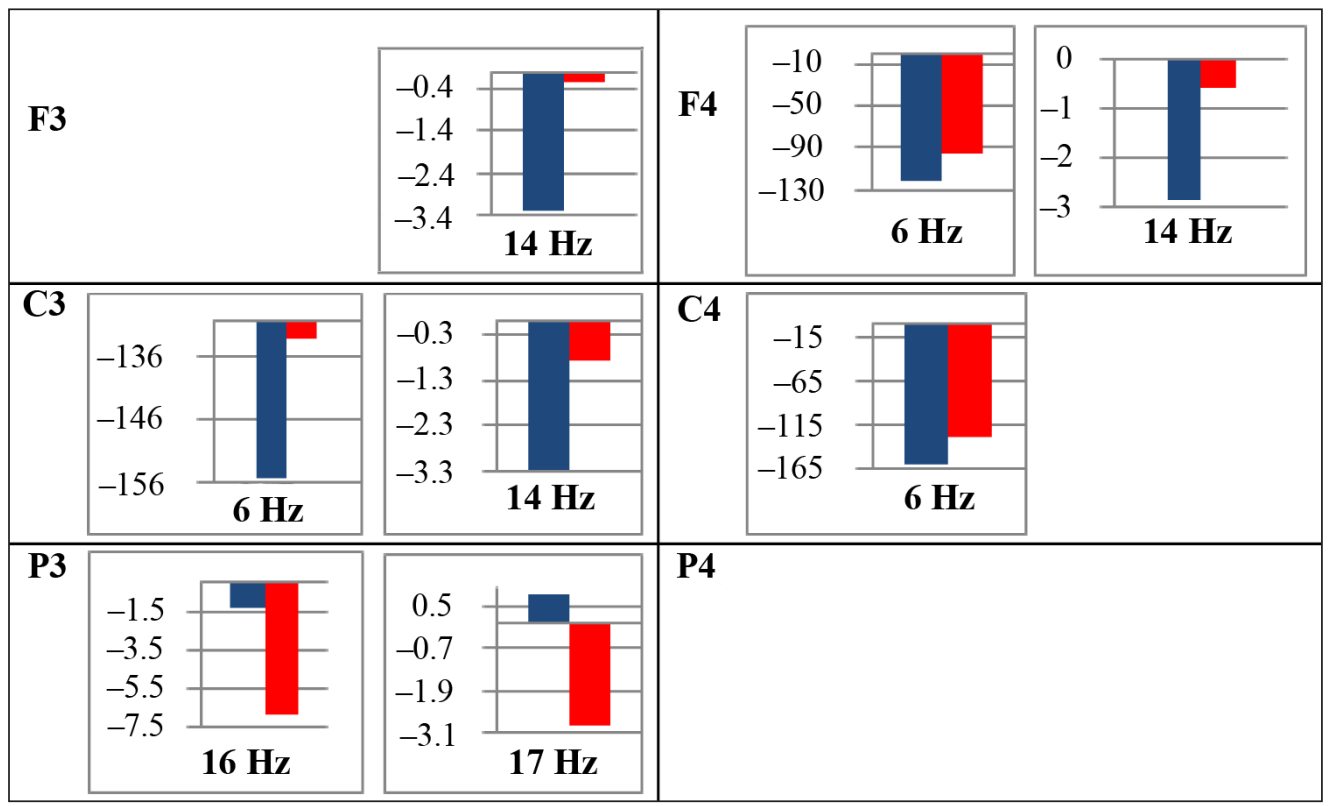

Fig. 5. Spectral power EEG changes in men compared with Go and Stop-Change responses. Significant differences ( $p$-level $\leq 0.05$ ) obtained by comparing the values of spectral power changes (in relative units) in post-stimulative intervals (during sensorimotor response) spectrogram at Go (red) and Stop-Change (blue) response; F3, F4, C3, C4, P3, $\mathrm{P} 4$ - the studied leads. The calculation of changes in the SP was carried out in accordance with the method proposed by Pfurtscheller \& Lopes da Silva (1999), where the negative values correspond to the ERS and positive values correspond to the ERD.

\section{DISCUSSION}

The aim of our study was to assess synchronization/desynchronization of SP EEG frequency spectrum in terms of breaking the motor program of manual movement, followed by switching to alternative go-response.

The ERD reaction was revealed in the lower $\alpha$-frequency range $(7-8 \mathrm{~Hz})$ of EEG in symmetrical frontal and central areas of the cortex. It can serve as a specific electrophysiological correlate of the activation of the cortical structures responsible for creating (including switching) and start of the motor program of manual movements (Haaland et al., 2000; Ziemann, Hallett, 2001; Joffe, 2003; Ou Bai, 2005; Neubauer et al., 2006).

The growth of EEG power at the frequency of $9 \mathrm{~Hz}$ in the left parietal lobes contralateral to the working right hand was an interesting fact. This pattern serves, perhaps, as some evidence of cortical deactivation related to the function of sensory-spatial attention of a manual movement and the need for restructuring the previous motor installation. The pattern can be consistent with the results we obtained in our previous research on the increase of the capacity of the upper $\alpha$-subrange of EEG in terms of the situation of sequential movements of fingers (Morenko et al., 2013).

Significant changes in terms of breaking the motor program and its switching to the alternative in the $\beta$-subrange of EEG were determined. We detected synchronization of electrical activity at lower $\beta$-frequencies $(14-15 \mathrm{~Hz}$ ) in the frontal, central and right parietal areas and at upper $(22 \mathrm{~Hz}) \beta$-rate frequencies of EEG in the right frontal leads. According to the literature, these patterns can serve as a criterion for enhancing mental tension (Wróbel, 2000), increasing the role of "differentiated attention" (Petsche, 1996). It is a process that promotes 
a closer interaction between widely distributed neural networks, which are involved in the processing. It should be noted that an event-related synchronization of EEG oscillations at the frequency of $14-15 \mathrm{~Hz}$ (in frontal and central areas) is significantly higher, and at the frequency of $16-17 \mathrm{~Hz}$ (in the parietal lobes) is significantly lower than those in the go-response.

Thus, it was found that event-related synchronization of electrical cortical activity was the most sensitive to the stop of manual movement followed by switching to an alternative motor task. The event-related synchronization showed higher values of the spectral power than during the go-response, at the frequencies of $6 \mathrm{~Hz}$ and $14-15 \mathrm{~Hz}$ in frontal and central leads, which are a projection of prefrontal and primary motor cortex areas. However, the EEG synchronization process was lower at the frequency of $16-17 \mathrm{~Hz}$ in both parietal leads. In our opinion, such a pattern could hypothetically reflect the activities of cortical areas (prefrontal and primary motor cortex), which are involved to the inhibition movements followed by the launch of the alternative motor program.

\section{CONCLUSIONS}

1. A significant ERS response is established at the frequency of $6 \mathrm{~Hz}$ in symmetrical frontal, central and parietal parts, at $9 \mathrm{~Hz}$ frequency - in the left parietal area, at $14-15 \mathrm{~Hz}$ - in frontal, central and parietal areas of the right cortex, and at the frequency of $22 \mathrm{~Hz}$ - in the right frontal lead. Instead, at the frequency of 7-8 Hz, EEG desynchronization is recorded in the frontal and central areas of both hemispheres.

2. The event-related synchronization of electrical cortical activity was the most sensitive to the stop of manual movement followed by switching to an alternative motor task. The event-related synchronization showed higher values of the spectral power at the frequency of $6 \mathrm{~Hz}$ and at $14-15 \mathrm{~Hz}$ in frontal and central leads and was lower than during the goresponse at the frequency of $16-17 \mathrm{~Hz}$ in both parietal lobes.

\section{ACKNOWLEDGEMENTS}

Research was performed under the research project funded by the state budget of Ukraine (Reg. No. 0111U002143).

Received 2 May 2017

Accepted 21 November 2017

\section{References}

1. Bai O, Mari Z, Vorbach S, Hallet M. Asymmetric spatiotemporal patterns of event-related desynchronization preceding voluntary sequential finger movements: a high-resolution EEG study. Clinical Neurophysiology. 2005; 116(5): 1213-21.

2. Band GP, van Boxtel GJ. Inhibitory motor control in stop paradigms: review and reinterpretation of neural mechanisms. Acta Psychologica. 1999; 101(2-3): 179-211.

3. Boecker M, Drueke B, Vorhold V, Knops A, Philippen B, Gauggel S. When response inhibition is followed by response reengagement: an event-related fMRI study. Human Brain Mapping. 2011; 32(1): 94-106.

4. Boecker M, Gauggel S, Drueke B. Stop or stop-change - does it make any difference for the inhibition process? International Journal of Psychophysiology. 2013; 87: 234-43.

5. Camalier CR, Gotler A, Murthy A, Thompson KG, Logan GD, Palmeri TJ, et al. Dynamics of saccade target selection: race model analysis of double step and search step saccade production in human and macaque. Vision Research. 2007; 47(16): 2187-2211.

6. De Jong R, Coles MG, Logan GD. Strategies and mechanisms in nonselective and selective inhibitory motor control. J Exp Psychol Hum Percept Perform. 1995; 21(3): 498-11.

7. Haaland KY, Harrington DL, Knight RT. Neural representations of skilled movement. Brain. 2000; 123 (Pt 11): 2306-13.

8. Ioffe ME. Neural basis of learning new movements: evolution of classical concepts. Journal 
of higher nervous activity. 2003; 53(1): 5-21. Russian.

9. Klimesch W, Sauseng P, Hansmayr S. EEG alpha oscillations: The inhibition-timing hypothesis. Brain Research Reviews. 2007; 53(1): 63-88.

10. Krämer UM, Knight RT, Münte TF. Electrophysiological evidence for different inhibitory mechanisms when stopping or changing a planned response. J Cogn Neurosci. 2011; 23(9): 2481-93.

11. Lizogub VS, Kozhemyako TV, Yukhimenko LI, Khomenko SM. [Electrophysiology characteristics of $\mathrm{P}_{300}$ and the functional organization of complex audiomotory reactions at adolescents]. Cherkasy University Bulletin: Biological Sciences Series. 2015; 2(335): 72-8. Ukrainian.

12. Logan GD. On the ability to inhibit thought and action. A user's guide to the stop-signal paradigm. In: Dagenbach D, Carr TH, editors. Inhibitory process in attention, memory and language. San Diego: Academic Press; 1994. p. 189-239.

13. Morenko AG, Pavlovuch OS, Kotsan IYa. [Features of cortical activation processes in men during auditorymotor activity of different complexity]. Fiziologichnyj Zhurnal. 2013; 59(5): 41-9. Ukrainian.

14. Neubauer AC, Fink A, Grabner RH. Sensitivity of alpha band ERD to individual differences in cognition. Progress in Brain Research. 2006; 159: 167-78.

15. Petsche H. Approaches to verbal, visual and musical creativity by EEG coherence analysis. International Journal of Psychophysiology. 1996; 24(1-2): 145-59.

16. Pfurtscheller G, Lopes da Silva FH. Event-related EEG/MEG synchronization and desynchronization: basic principles. Clinical Neurophysiology. 1999; 110(11): 1842-57.

17. Rangel-Gomez M, Knight RT, Krämer UM. How to stop or change a motor response: Laplacian and independent component analysis approach. International Journal of Psychophysiology. 2015; 97(3): 233-44.
18. Verbruggen F, Schneider DW, Logan GD. How to stop and change a response: the role of goal activation in multitasking. Journal of Experimental Psychology Human Perception and Performance. 2008; 34(5): 1212-28.

19. Wróbel A. Beta activity: a carrier for visual attention. Acta Neurobiological Experimentalis. 2000; 60(2): 247-60.

20. Zhavoronkova LA. [The right-handed and the left-handed: hemispheric asymmetry of the human brain biopotentials]. Krasnodar: Jekoinvest; 2009. Russian.

21. Ziemann U, Hallet M. Hemispheric asymmetry of ipsilateral motor cortex activation during unimanual motor tasks: further evidence for motor dominance. Clinical Neurophysiology. 2001; 112: 107-13.

Korzhyk Olha, Pavlovych Olha, Shvarts Lyudmyla, Shevchuk Tetyana, Dmytrotsa Olena, Poruchynskiy Andriy, Morenko Alevtyna

\section{RANKŲ ATSITIKTINĖ SINCHRONIZACIJA / DESINCHRONIZACIJA VYRŲ GALVOS SME- GENŲ MOTORINĖJE ZONOJE}

\section{Santrauka}

Mokslo visuomenèje didèja susidomèjimas smegenų procesais galvos smegenų motorineje zonoje. Eksperimente dalyvavo 32 vyrai 18-23 metų amžiaus. Tiriamiesiems su užrištomis akimis rankomis vykdant veiksmus „Go-Stop-Change“, buvo atlikta elektroencefalografija (EEG) pagal 10/20 tarptautinę sistemą. Esant žemam tonui (70\%), vyrai turèjo paspausti kairị konsolès mygtuką dešiniu rodomuoju pirštu. Atsiradus aukštam tonui (30 \%), reikejjo greitai paspausti viduriniu pirštu dešini mygtuką. Matlab aplinkoje buvo įvertintas su îvykiu susijusios desinchronizacijos ir sinchronizacijos spektrinès galios EEG dažnis (7-23 Hz). Nustatytas reikšmingas (su ịvykiu susijusi sinchronizacija) atsakas skirtingu dažniu $(6,9,14-15,22 \mathrm{~Hz})$ skirtingose smegenų srityse. EEG desinchronizacija buvo registruota 7-8 Hz dažniu.

Raktažodžiai: pirštų judesiai, spektrinè galia, elektroencefalografija, dažnių spektras 